\title{
Os rumos do Ensino Superior brasileiro em contexto de crise: da Declaração de Córdoba aos cortes no orçamento das Universidades
}

\section{Liziane Soares Guazina}

Professora de graduação e pós-graduação da Faculdade de Comunicação da Universidade de Brasilia (UnB).

E-mail: lguazina@unb.br

Dione Oliveira Moura

Professora de graduação e pós-graduação da Faculdade de Comunicação da Universidade de Brasilia (UnB).

E-mail: dioneoliveiramoura@gmail.com

Resumo: Marco Antônio Rodrigues Dias, autor da obra Ensino superior como bem público: perspectivas para o centenário da Declaração de Córdoba, concedeu uma entrevista na qual reflete sobre o passado, presente e futuros possíveis para o ensino superior no Brasil. Professor aposentado da UnB, Dias é ex-diretor da Divisão da Educação Superior da Organização das Nações Unidas para Educação, Ciência e Cultura (Unesco) em Paris (1981-1999). Na entrevista, ele discute sobre a educação superior como bem público e, também, pondera as forças operantes nos últimos anos no modelo privado de ensino superior no Brasil.

Palavras-chave: ensino superior; universidade pública; bem público; modelos de financiamento; crise.
Abstract: Marco Antônio Rodrigues Dias, author of the work Higher education as a public good: prospects for the centenary of the Declaration of Cordoba, gave an interview in which he reflects on the past, present and possible futures for higher education in Brazil. Dias is a retired professor of the University of Brasilia (UnB) and former director of the Division of Higher Education of the United Nations Educational, Scientific and Cultural Organization (Unesco) in Paris (1981-1999). In the interview, he discusses higher education as a public good and also considers the last years operating forces in the private model of higher education in Brazil.

Keywords: higher education; public university; public good; financing models; crisis. 
A crise orçamentária do ensino superior brasileiro ganhou contornos dramáticos em 2019, quando o chamado "Future-se", projeto proposto pelo Ministério da Educação, apontou para uma mudança profunda no modelo de financiamento das universidades públicas federais. No entanto, as universidades já vinham atravessando momentos de cortes profundos de recursos desde a aprovação, em dezembro de 2016, da Emenda Constitucional n ${ }^{\circ} 95$ (mais conhecida como PEC do Corte de Gastos) no Congresso Nacional, que restringiu boa parte das verbas de custeio e investimentos, comprometendo o pagamento de bolsas de pesquisa e a realização de projetos de ensino, pesquisa e extensão.

No auge do debate sobre os cortes orçamentários que levaram, inclusive, a protestos e ocupações estudantis, realizamos, em 2018, uma entrevista, por $\boldsymbol{e}$-mail, com Marco Antônio Rodrigues Dias, ex-professor e ex-vice-reitor da Universidade de Brasília nos anos 1970. Dias foi diretor da Divisão de Ensino Superior da Unesco, em Paris, de 1981 a 1999. Nesta função, foi o coordenador principal da Conferência Mundial sobre Ensino Superior em 1998 e quem lançou, em 1992, o programa UNITWIN-Cátedras Unesco. De 2001 a 2009, foi assessor especial do reitor da Universidade das Nações Unidas e representou esta organização em Paris. Autor de inúmeros artigos sobre educação, comunicação e política em diversos países, colaborou com instituições de todos os continentes. Recebeu diversas medalhas e condecorações, entre elas a Légion d'honneur francesa (1999) e a Ordem do Mérito Educativo no Brasil (1993). Em 2005, recebeu o título de doutor honoris causa da Universidad Nacional del Noroeste de la Província de Buenos Aires (pública); em 2009, da Universidade Federal do Mato Grosso; e em 2017 da Universidad Nacional de Córdoba. Em 2018, juntamente com Rafael Guarga, ex-reitor da Universidade da República do Uruguai, no dia das comemorações do Centenário das Reforma de Córdoba de 1918 (15 de junho de 2018), recebeu, em Córdoba, a distinção "Centenário da Reforma Universitária” por serem considerados, os dois, representantes atuais do espírito da reforma que marcou o conjunto do sistema universitário do continente: educação superior como bem público, acessível a todos, livre e responsável e vinculada à solução dos problemas da sociedade em seu conjunto.

As reflexões de Marco Antônio Rodrigues Dias continuam cada vez mais atuais, pois mostram que as recentes propostas governamentais de radicais alterações no modelo de financiamento público do ensino superior brasileiro trazem, em si, uma concepção bem diferente da educação como um bem público, e já estavam presentes em muitos dos embates sobre o papel do ensino superior no desenvolvimento de diferentes países, inclusive no Brasil.

Tendo em vista o agravamento da situação da educação no Brasil, retomamos a entrevista em dezembro de 2019, e mais questões foram enviadas ao professor Dias relativas a sua avaliação da proposta "Future-se", apresentada em 2019 pelo MEC, e a sua análise do posicionamento da Andifes (Associação Nacional dos Dirigentes das Instituições Federais) frente ao projeto.

Em sua resposta, Dias considera o Future-se prejudicial ao país. Embora a discussão sobre a iniciativa seja importante, destaca o professor, deve-se levar 
1.RODRIGUES DIAS, M A. Ensino superior como bem público: perspectivas para o centenário da Declaração de Córdoba. Montevidéu: Asociación de Universidades Grupo Montevideo, 2017. Disponível em: http://grupomontevideo.org/sitio/wp-content/ uploads/2017/08/Miolo Educacao-Superior-comoBem-Publico CORRETO. pdf. Acesso em: 2 dez. 2019.

2.Ao proferir a conferência de abertura do IX Encontro de Redes de Educação Superior e Conselhos de Reitores da América Latina e do Caribe, em Lima, Peru, no dia 13 de março de 2019, o professor Dias voltou a tratar do tema, incluindo elementos adicionais, como o exame da reutilização da doutrina de segurança nacional nas instituições de ensino superior do continente nos dias de hoje. (Las nuevas generaciones frente al oscurantismo y al retroceso. Integración y Conocimiento v. 8, n. 2, p. 78-93, 2019.) em conta que o diálogo em torno da proposta é falso, pois, em sua opinião, o atuais administradores do país já decidiram pela privatização das instituições públicas. Há, portanto, um simulacro de negociações. Para Dias, o Future-se liquida com a ideia de educação como bem público, enterra o princípio constitucional da autonomia, e entrega a formação de nossa juventude a grupos cujo único objetivo é a comercialização e o lucro.

\section{Comunicação $\mathcal{E}$ Educação: O que significa definir a educação superior como bem público?}

Marco Antônio Rodrigues Dias: Este é o tema central de meu livro Ensino superior como bem público: perspectivas para o centenário da Declaração de Córdoba, que a Associação de Universidades Grupo de Montevidéu e universidades dos países vinculados ao Mercosul lançaram em 2016, em versão escrita em espanhol (com a Universidade da República em Montevidéu) e em português (com a Universidade Federal de Santa Maria) e divulgaram também em inglês no site da AUGM ${ }^{1}$.

Estou seguro de que os historiadores do futuro, ao analisarem o fim do século XX e o início do século XXI, irão falar de um período dominado pelo obscurantismo, em que, ao mesmo tempo, um desenvolvimento enorme da ciência e da tecnologia esteve acompanhado de um aumento exponencial da separação entre grupos e classes e do fortalecimento da precariedade para grande parte da humanidade ${ }^{2}$.

No que diz respeito ao ensino superior, no livro, relembro que, em escala mundial, sempre existiram duas racionalidades que fundamentam a ação das instituições, que podem ser tratadas como: (a) um serviço público, prestado, sobretudo, pelos governos, mas que também pode ser proporcionado por outras instituições no marco de sistemas de concessão, delegação ou autorização (essa é a concepção que predominou durante a Conferência Mundial sobre o Ensino Superior, em Paris, em 1998); e (b) empresas organizadas para vender produtos aos que podem pagá-los. Os estudantes, neste caso, são vistos como clientes. É o modelo anglo-saxônico, que, agora, se busca espalhar por todo o mundo e que, no Brasil, predomina desde há algumas décadas.

Vocês indagam sobre a evolução deste conceito e sobre minha experiência profissional nesta área. Num país, como o Brasil, nos últimos tempos, não há uma evolução; há, diríamos, uma "involução", uma marcha a ré descomunal. Mas desfaçamos, desde logo, um equívoco. Confundem-se muitas vezes os conceitos de serviço público (missão) e setor público (estatuto). O conceito de bem público não elimina a possibilidade de concessão, delegação ou autorização, inclusive em benefício de empresas privadas, mas implica que os beneficiários dessas medidas se submetam a normas que privilegiem o interesse coletivo. Também requer a existência de mecanismos que obriguem os prestadores do serviço a encargos (cahier de charges, em francês), sendo o controle realizado por autoridades legítimas, democraticamente eleitas. 
Isto é concessão a grupos privados ou monopolistas? Nada disso. Simplesmente, não há de se deixar de tomar em conta que, em determinados momentos, em alguns países, as instituições de ensino superior públicas ou estatais, sem disporem de um sistema que lhes garanta autonomia, tornam-se instrumentos também de dominação e de manutenção de privilégios. Mesmo na América Latina, onde as universidades incorporaram à sua natureza, à sua essência, o conceito de autonomia, isto ocorre.

No final dos anos 1970, quando estudantes da UnB foram expulsos arbitrariamente, alguma instituição pública teve condições de aceitar a transferência de um só destes estudantes? Instituições que o fizeram, como a PUC de São Paulo, enfrentaram o veto dos militares e responderam positivamente à mediação do professor da UnB, o Padre Aleixo, que, neste caso, atuou juntamente com dirigentes da Confederação Nacional do Bispos do Brasil (CNBB) da época. Que instituição, neste momento, agiu com mais espírito público?

É evidente, no entanto, que não se pode ser ingênuo. A maioria das instituições privadas, hoje, no Brasil, tem como objetivo primordial, eu diria único, o lucro. A educação para eles é negócio. Liberdade, neste caso, não significa buscar livremente alternativas para a construção de um país democrático que defenda a igualdade para todos. Representa, sim, fazer negócio e responder aos interesses dos grupos que controlam a vida política e econômica do país. Contudo, dirão alguns: quem conseguirá que instituições particulares aceitem um compromisso de liberdade, de responsabilidade social, de construção de um país livre e democrático? Isto, evidentemente, é função de governos, mas de governos democráticos. Em ditadura real ou disfarçada, evidentemente, não há solução. O que vai ocorrer é o que se passa em muitos países, em particular na América Latina. Essa concepção é reforçada por organizações internacionais que se baseiam nos princípios do Consenso de Washington.

Em 1989, numa conferência organizada em Washington pelo Instituto de Economia Internacional (IIE), o economista inglês John Williamson forjou os princípios do Consenso de Washington: privatização, liberalização econômica, desregulamentação e controle da inflação e do déficit público. O Consenso de Washington foi, pois, uma criação do final da década de 1980 de três instituições com base na capital dos Estados Unidos: Fundo Monetário Internacional (FMI), Banco Mundial e o Tesouro dos EUA.

O Banco Mundial - seguido por organizações como a Organização para Cooperação e Desenvolvimento Econômico (OCDE), o FMI e, mais tarde, a Comissão Europeia e a Organização Mundial do Comércio (OMC) - foi o agente principal na promoção da adaptação ao ensino superior dos princípios econômicos do Consenso de Washington, e, por conseguinte, pôs-se a defender: a redução do montante de investimentos no ensino superior; o estímulo à educação privada, considerada um instrumento para se alcançar equidade; a aceitação do princípio segundo o qual a educação superior é considerada um objeto comercial; e a regulação dos sistemas educativos em conformidade com princípios consolidados mais tarde no âmbito da OMC. 
3.ONU. Declaração Universal dos Direitos Humanos. 1948. Disponível em: http://www.direitoshumanos.usp.br/index. php/Declara\%C3\%A7\%C3\%A3o-Universal-dos-Direitos-Humanos/declaracao-universal-dos-direitos-humanos.html. Acesso em: 15 out. 2020

4.BRASIL. Decreto $n^{\circ}$ 591, de 6 de julho de 1992. Atos Internacionais. Pacto Internacional sobre Direitos Econômicos, Sociais e Culturais.

Promulgação. Disponível em: http://www.planalto. gov.br/ccivil_03/decreto/ 1990-1994/d0591.htm. Acesso em: 15 out. 2020.

5.SGUISSARDI, V. Estudo diagnóstico da política de expansão da (e acesso à) educação superior no Brasil: 20022012. Brasília: SESU; Projeto de Organismo Internacional - OEl; Projeto OEI/BRA/10/002, 2014; SGUISSARDI, V. Educação superior no Brasil: democratização ou massificação mercantil?. Educação \& Sociedade, Campinas, v. 36, n. 133, p. $867-889$ out.-dez. 2015.
Até então, o sistema das Nações Unidas, em particular a Unesco, sempre considerara a educação como um direito humano, destinado a todos e a cada um, em síntese um bem público, tomando como referência a Declaração Universal dos Direitos Humanos, adotada e proclamada pela resolução 217 A (III) da Assembleia Geral das Nações Unidas, em 10 de dezembro de 1948.

Artigo 26. Toda pessoa tem direito à instrução. A instrução será gratuita, pelo menos nos graus elementares e fundamentais. A instrução elementar será obrigatória. A instrução técnico-profissional será acessível a todos, bem como a instrução superior, esta baseada no mérito ${ }^{3}$.

Esse dispositivo foi reforçado pelo artigo 13, parágrafo $1^{\circ}$, do Pacto Internacional dos Direitos Econômicos, Sociais e Culturais, adotado pela Assembleia Geral das Nações Unidas em dezembro de 1966, e ratificado por inúmeros países, inclusive pelo Brasil, que, com respeito ao ensino superior, diz: "A educação de nível superior deverá igualmente tornar-se acessível a todos, com base na capacidade de cada um, por todos os meios apropriados e, principalmente, pela implementação progressiva do ensino gratuito"4.

Este Pacto está em vigor, mas ninguém fala dele, muitos o desconhecem, e os que dele têm conhecimento procuram escondê-lo. É compromisso legal firmado pelos membros das Nações Unidas, inclusive pelo Brasil. São essas posições, ancoradas na Declaração Universal dos Direitos Humanos e fundamentais no sistema das Nações Unidas desde sua criação, que se busca, nos dias de hoje, por terra.

\section{CEEE: E no Brasil, o que se passa, efetivamente, nos últimos anos?}

MARD: Assinalemos algo positivo. A situação de inclusão social melhorou muito no Brasil entre 2010 e 2014, em seguida à adoção pelo governo brasileiro de então da política de cotas em benefício de minorias e de outras políticas de inclusão social. Em 18 de agosto de 2016, o jornal O Estado de S.Paulo publicou matéria de Lígia Formenti, Isabela Palhares e Victor Vieira com o título "2 em 3 alunos de universidades federais são das classes D e E".

No entanto, há o outro lado da medalha. Um professor da Universidade Federal de São Carlos, Valdemar Sguissardi, elaborou, por solicitação da Secretaria de Ensino Superior do Ministério de Educação do Brasil (SESU), "um estudo diagnóstico da política de expansão da (e acesso à) educação superior no Brasil - 2002-2012" . Os dados apresentados são estarrecedores. Embora o Plano Nacional de Educação brasileiro (2001-2010) previsse atingir-se no país uma taxa líquida de 30\% de matrículas de graduação até 2012, apenas se ultrapassou metade desse índice (15,3\%). O novo PNE estabelece uma meta de $33 \%$ para o decênio 2014-2024. Em 2012, as matrículas de graduação (presencial e a distância), no total de 7.037.688, assim se distribuíam: 26,9\% nas IES públicas e $73,1 \%$ nas privadas.

Com base nos dados apresentados por Sguissardi, pode-se verificar que, no Brasil, mais de $80 \%$ das instituições de ensino superior têm fins lucrativos, 
são comerciais, e têm em suas empresas mantenedoras grupos econômicos poderosos nacionais e estrangeiros e inclusive uma divisão do Banco Mundial, The International Finance Corporation. Elas se regem pelas leis do comércio e controlam as matrículas da maioria dos estudantes do país.

$C \mathcal{E} E$ : Percebe-se um clima político polarizado em que atores sociais cada vez mais proeminentes atacam a ideia de liberdade e autonomia universitárias. Como você observa esses últimos anos? Você defende que a ideia de autonomia implica diferentes elementos: liberdade de pesquisa, liberdade de ensino, poder de autogestão. Como é possível para os gestores das universidades brasileiras enfrentarem o engessamento no uso dos recursos decorrente da PEC do Teto de Gastos e garantirem uma autogestão minimamente autônoma e eficiente?

MARD: Que o clima esteja polarizado no Brasil, não há dúvidas. E quando a polarização se torna extrema, comportamentos irracionais se desenvolvem de maneira incrível. Basta olhar, hoje, as postagens no Facebook para se dar conta do fenômeno. De um lado, estão todos agindo na base do "quem não pensa como eu é contra mim”. Não é necessariamente o caso. O contraditório é fundamental em uma democracia. O que se vê, hoje, é uma situação pior que aquela do início dos anos 1950, quando fanáticos liderados por Carlos Lacerda incendiavam o país, e muitos de nós, sem saber o que estava por trás daquilo tudo, submetíamo-nos a uma política moralista que acabou dando no golpe de 1964 e na supressão da liberdade durante mais de vinte anos. E os que controlavam o poderio econômico em seguida à Segunda Guerra Mundial deixavam o trabalho sujo para ser feito pelos militares e continuavam beneficiando-se das medidas econômicas e financeiras que eles controlavam junto com grupos internacionais. E ainda há quem diga que a história não se repete...

Para completar a resposta a estas questões, permitam-me dizer duas coisas:

1. Seguramente, não é fácil ser administrador universitário nos dias de hoje. É certo que as universidades devem desenvolver um esforço permanente para ser mais eficientes do ponto de vista de gestão. Todo desperdício deve ser evitado. O rigor na aplicação de fundos públicos tem de ser a regra. Mas não se deve esquecer que universidade não é fábrica de sabão. As empresas, no regime capitalista, organizam-se para ter lucros. As universidades visam objetivos sociais. São de natureza diferente e devem ser tratadas de maneira específica. Em termos concretos, uma universidade deve distinguir entre suas unidades voltadas às finanças e à economia, e suas funções principais que são de natureza escolar e que visam formação e pesquisa, serviços que não podem sempre, como nas empresas capitalistas, visar eficácia vista como sinônimo de lucro financeiro. Devem manter sua capacidade crítica, devem prestar serviços à comunidade, devem colaborar com o desenvolvimento da sociedade em seu conjunto, devem estimular o acesso e a mobilidade, e não apenas, como nas empresas, favorecer os interesses de seus proprietários, acionistas e, eventualmente, conceder alguns benefícios a seus empregados.

2. Esta história de congelar gastos em educação e em ciência e tecnologia só pode vir de quem dispõe de um projeto de nação submissa. É inaceitável. 
É o contrário do que vem fazendo a China, por exemplo ${ }^{6}$. Há que gritar isso por todas as maneiras possíveis. O mesmo vale para um contingenciamento cego que só poderá ter como resultado o asfixiamento da capacidade de ação das universidades. Quanto à utilização de recursos próprios da universidade, as medidas descritas por vocês são absurdas. Durante o regime militar, nos anos 1970, enfrentamos este problema na UnB. Estimulou-se a universidade a produzir recursos próprios, o que era feito principalmente com trabalhos de pesquisa para empresas públicas e organização de cursos e treinamentos para funcionários de diversos grupos. Os professores queriam utilizar os recursos para melhorar seus programas, mas, na época, o administrador era um militar originário da área de segurança, e, em consequência, todos estes recursos iam para um fundo que este senhor administrava segundo critérios pouco conhecidos. Se isto não mudar, administrar uma universidade pública tornar-se-á impossível.

$C \mathcal{E} E$ : Há saídas para o modelo atual de financiamento das universidades brasileiras que não implique privatização ou fechamento de ofertas de cursos e serviços? Quais modelos de financiamento das universidades predominam hoje no cenário internacional?

MARD: Esse foi o tema mais difícil da Conferência Mundial sobre o Ensino Mundial, da Unesco, em Paris, em 1998. Os efetivos do ensino superior multiplicaram-se exponencialmente, enquanto, ao mesmo tempo, os recursos, principalmente financeiros, diminuíram numa proporção assustadora. Isso leva certos analistas, representantes de organizações internacionais e muitos políticos de visão curta a defenderem então a saída da privatização, que seria a solução para os problemas financeiros do governo - e, ainda mais, pasmem, seria democrática.

O sistema de cobrança de anuidades é, em muitos casos, a solução fácil para administradores sem imaginação ou para funcionários internacionais que enviam seus filhos a colégios caríssimos e, depois, têm os custos reembolsados por suas organizações. Em alguns países, a adoção do ensino universitário pago provocou mais exclusão, alguns falam mesmo de verdadeiro apartheid social. Pesquisas do Instituto de Educação de Londres revelam os efeitos sociais nefastos dessas políticas em países como Estados Unidos e Reino Unido. A pesquisa nos Estados Unidos demonstra claramente que os empréstimos estudantis têm um impacto negativo/desincentivo sobre a participação de grupos de baixa renda por causa da dívida concomitante dos estudantes, mas neutro na dos grupos de renda média a alta. Em contrapartida, os subsídios têm um resultado positivo na matrícula de grupos de baixa renda e um resultado neutro para grupos de renda média a alta. $\mathrm{E}$ as taxas de matrícula têm um efeito de desincentivo sobre os alunos pobres e de renda média, mas não têm impacto algum entre os estudantes de alta renda.

A correção do sistema por meio de medidas como bolsas, crédito educativo ro. O ensino superior (e o projeto de nação) da China para além dos clichês. Jornal da Unicamp, Campinas, n. 389, p. 6-7, 24-30 mar. 2008.

e outras, como advogado pelos organismos financeiros, também não é simples. Mesmo em países democráticos, frequentemente os beneficiados são os que 
menos necessitam, valendo mais os contatos políticos que a privação de recursos. Armando Mendes, um economista e educador brasileiro já falecido, professor da Universidade Federal do Pará (UFPA), e durante algum tempo também da UnB, estudou a solução fiscal que poderia ser tentada e, no final, defendeu que, em países como o Brasil, seria necessário: assegurar o acesso aos mais pobres; ampliar as fontes de recursos das universidades; e integrar as famílias dos mais ricos no esforço pela ampliação dos recursos destinados à educação (através do mecanismo do imposto de renda).

Na mesma linha de não instituir uma cobrança generalizada, mas de utilizar recursos fiscais, duas sugestões merecem um exame frio e objetivo:

(a) a do professor Rodolfo Pinto da Luz, um antigo dirigente universitário, ex-secretário da Sesu no MEC e ex-reitor da UFSC, que, em documento apresentado à CMES, em Paris, em 1998, sugeriu que se atribuísse ao desenvolvimento do ensino superior um montante que seria proveniente de um percentual de um imposto;

(b) A do Andes - o Sindicato Nacional dos Docentes do Ensino Superior no Brasil -, que, em seu congresso de Fortaleza, em 1999, segundo seu ex-presidente, Renato de Oliveira, sugeriu a criação de taxas sobre setores duros da economia (petróleo, energia, comunicação etc.) para se desenvolver um fundo que asseguraria o desenvolvimento do ensino superior e da pesquisa.

Muitos economistas concentram o debate nas diferenças entre os índices de retorno sociais e privados (social and private rates of return), comparando o que ganham os indivíduos com os benefícios que recebe a sociedade com as inversões realizadas nos diversos níveis de educação. Através de análises em que sofismas se multiplicam, defendem que os rendimentos para a sociedade são mais importantes quando se aplicam na educação primária e, utilizando um atalho muito ligeiro, concluem que os países em desenvolvimento não devem considerar a educação superior como prioritária e que, ao contrário, devem eliminar, ou reduzir ou pelo menos não dar prioridade a gastos nesse nível de ensino.

Peter Atherton, um professor canadense prematuramente falecido (Brock University), recordava que esse método de análise trata o custo econômico da educação como uma inversão e o compara com as vantagens econômicas. Uma taxa de rentabilidade pessoal (vantagens mais altas para a vida) expressa o rendimento da inversão do indivíduo em sua própria instrução (direitos, materiais e anos de sacrifício etc.). Uma taxa de rentabilidade social revela o rendimento da inversão total em educação (gastos públicos para programas de formação sob a forma de subvenções diversificadas). A metodologia é semelhante à que se utiliza para estimar o valor atual de um montante que um indivíduo receberá mais tarde como resultado de seus investimentos, poupanças e aplicações.

No entanto, muitos, insuflados por técnicos de organizações internacionais, buscam, em modelos estrangeiros, desligados de suas realidades, a solução para seus problemas. Há um fascínio absoluto em certos meios com relação ao modelo estadunidense ou inglês. Periódicos como o The Economist 
frequentemente analisam a situação. Foi o que ocorreu em 16 de novembro de 2000 e, sobretudo, em 14 de novembro de 2002, com um artigo detalhado sobre a ruína das universidades inglesas.

No verão de 1999, os jornais ingleses publicaram uma série de fatos relativos a distorções do sistema inglês. Seria longo mencioná-los todos. Limitemonos à edição do domingo, 26 de julho de 1999, do Sunday Times, quando esse periódico chamava atenção para o fato de que "as universidades obtêm dinheiro vendendo títulos honoríficos”. O jornalista informava, com detalhes, que "as universidades concedem graus honorários a pessoas ricas em troca de dinheiro" e que "homens de negócio podem comprar um doutorado por apenas $10 \mathrm{mil}$ libras”. O jornal explicava que sua atenção havia sido despertada pelo fato de, na Inglaterra, nos últimos tempos, verificar-se um aumento da concessão de títulos honoríficos. Até a multicentenária e prestigiosa Universidade de Oxford agia dessa maneira. Mas o preço, evidentemente, era muito mais caro: $250 \mathrm{mil}$ libras. A mensagem é clara. Neste Reino Unido, para sobreviver, com a diminuição dos fundos públicos para educação superior, devem-se produzir recursos. Os instrumentos para isso contam pouco. O que importa é o resultado. Tudo isto revela um cinismo descarado.

CEEE: Por fim, refletindo sobre este quadro sócio-histórico e político que você nos expôs nas respostas anteriores, como avalia o atual momento das universidades brasileiras? Quais são os possíveis cenários futuros?

MARD: O mínimo que se pode dizer é que é um momento difícil. E, como consequência, como já assinalei, muitos tendem a buscar fora a solução dos problemas, e, adotando o comportamento de vira-lata tão bem definido por Roberto Amaral, buscam em modelos desligados de nossas realidades a solução para os problemas das universidades.

Há uma fascinação pelo modelo inglês. Isto é brincadeira de mau gosto. Há pontos positivos no modelo, sem dúvida, mas, além do aspecto cultural, não nos esqueçamos de que, desde os tempos da senhora Thatcher, as universidades inglesas começaram a cobrar anuidades e a transformar bolsas em empréstimos. Ao mesmo tempo, o governo reduzia seus créditos para pesquisas e para a formação. A consequência foi imediata. Para satisfazer suas necessidades, as universidades são obrigadas a concentrar seus esforços em atividades comerciais e a consolidar uma filosofia que visa mais o lucro que o desenvolvimento do saber ou a expansão da cultura.

Quanto ao modelo dos Estados Unidos, em geral seus defensores centram a análise nos resultados dos rankings de instituições como Harvard, Stanford e MIT. Mas se esquecem de dizer que as próprias autoridades norte-americanas há muito consideram o sistema falido e que a grande maioria das instituições propicia hoje um ensino de qualidade discutível, e os estudantes, ao final dos cursos, estão de tal forma endividados que isso compromete a carreira de boa parte deles. 
Não é por outra razão que publicações como The Economist defendem o recrutamento de um número maior de estudantes estrangeiros (chineses, árabes e, até recentemente - acrescentamos - os brasileiros). Os estrangeiros pagam anuidades várias vezes superiores às dos ingleses e europeus. E isto explica o desfile lamentável de presidentes, primeiros-ministros e ministros no Brasil no tempo do Ciência sem Fronteira. Colaboração ou busca desesperada e desenvergonhada de recursos?

Uma saída para, pelo menos, melhorar a situação das universidades dos países em desenvolvimento viria da cooperação. Mas de que tipo de cooperação estamos falando? A Unesco comemorou, em outubro de 2017, os 25 anos do lançamento que fizemos, quando era diretor-geral o espanhol-catalão Federico Mayor, do programa UNITWIN-Cátedras Unesco. A ideia subjacente deste programa era a da democratização do saber, da divisão do conhecimento e da cooperação entre iguais.

Seu objetivo era favorecer a constituição de redes entre estabelecimentos de ensino superior nos níveis intrarregional, regional e sub-regional, com a finalidade de promover o desenvolvimento institucional e a distribuição de recursos e de facilitar as trocas de conhecimentos especializados e de dados de experiência como de pessoal e de estudantes.

Uma análise objetiva do sucesso e das dificuldades deste programa mostraria quão difícil é encontrar instituições e países que, de fato, estejam dispostas a colaborar, e não a dominar e explorar. Só alguns elementos para reflexão. Os países ricos, em 2005, tinham se comprometido a aplicar 0,7\% do seu PIB em programas e projetos de ajuda internacional ao desenvolvimento, mas chegaram ao início do século XXI com a média de 0,25\%. Estima-se que, com o desconto dos fundos fantasmas utilizados nos/e para os países ricos e seus consultores, essa ajuda, no que se refere aos membros do G-7 - Reino Unido, França, Estados Unidos, Alemanha, Canadá e Japão - reduz-se a 0,07\%. E, além disso, uma grande parte dos fundos destinados a cooperação é constituída de empréstimos, e não de doações ou subvenções.

Fazer o que o Brasil andou fazendo, ou seja, enviar estudantes a países ricos e à Austrália, sem contrapartida, sem assegurar que a formação servirá aos interesses do país, sem garantir o regresso do pessoal que envia para fora, é uma atitude de suicídio. Os países que fizerem isso estarão dando, de mão beijada, aos países ricos a possibilidade de recrutar os melhores cérebros, já com formação avançada. Uma política correta poderia ser a que adotou a China, que decidiu melhorar o equipamento de laboratórios de suas instituições, garantir melhores condições de trabalho a seus especialistas nacionais e condições de trabalho decente para os que terminam os estudos no exterior e regressam ao país. Estes, quando voltam, encontram estruturas adaptadas ao domínio de sua pesquisa e melhores perspectivas de carreira.

Um cenário negativo é o que se desenha para nossas instituições no presente momento. Há todo um esquema montado, em nível internacional, que, se mantido, 
conseguirá colaborar com o desmonte do Estado e com o pensamento único. É a consolidação do neocolonialismo versão século XXI.

\section{$C \mathcal{E} E$ : O que haveria de grave ou de problemático nessas questões?}

MARD: Uma lógica de natureza econômica e financeira, cujos critérios são essencialmente mercantilistas, opõe-se à concepção de serviço público baseada na Declaração Universal dos Direitos Humanos. Recentemente, The Economist citou o fundador de um MOOC (massive open online course), Udacity, que previu que "em 50 anos o número de universidades se reduziria a apenas dez"7. Evidentemente, não creio que isto ocorra, mas seu significado é claro. No entender desse senhor, universidades nacionais não serão mais necessárias. Todo o "serviço" será feito pelos MOOC. A formação de milhões de estudantes seria feita por pequenos grupos baseados em dois ou três países que, mesmo se utilizarem sócios nos países-objeto, controlarão todo o conteúdo e ainda toda a operação financeira. Seria um grande negócio, sem dúvida. E está claro que um dos produtos dessa operação seria a edificação de um sistema uniformizado de ensino superior em todo o mundo.

Tudo isto faz que aumentem de importância as discussões em torno de Córdoba [Reforma Universitária de Córdoba]. As novas gerações normalmente não têm conhecimento do que ocorreu em Córdoba em 1918. Em junho de 2018, comemorou-se o centenário da Declaração e da Reforma de Córdoba (1918), primeiro grande movimento, em nosso continente, a reformar em profundidade o sistema de ensino superior de um país, com influência posterior em toda a região. Córdoba mostrou quão importante é organizar e sistematizar um conjunto de princípios que se transformam em referência para as ações e podem ser usados como bandeiras para melhorar os sistemas. Córdoba estabeleceu os elementos básicos de ação para a defesa das liberdades acadêmicas e da autonomia universitária, um dos princípios que facilitaram a unidade das forças acadêmicas e a luta contra as ditaduras que, em particular nos anos 1960 e 1970, dominaram o continente com o sacrifício das liberdades, da dignidade humana, de gerações inteiras de latino-americanos.

À Reforma de Córdoba, devemos muito. O centenário de Córdoba deu-nos a oportunidade de retomar uma reflexão profunda sobre nossas sociedades e sobre o papel que nas transformações deve exercer o ensino superior. Uma nova declaração de Córdoba, nesta fase de nossa história, deverá contribuir para a formação de um cidadão consciente, que lutará, por todos os meios, por um desenvolvimento inclusivo, que não exclua nenhuma categoria de pessoa, e pela

7.THE ECONOMIST. Equipping people to say ahead of technological change. The Economist, Londres, p. 9, 14 jan. 2017. Disponível em: https://www. economist.com/leaders/ 2017/01/14/equippingpeople-to-stay-aheadof-technological-change. Acesso em: 2 dez. 2019. construção de uma sociedade mais justa.

CEEE: Como você avalia a proposta "Future-se" apresentada pelo MEC em 2019? O que a proposta significa no contexto da educação superior no Brasil e na América Latina? Qual sua análise sobre o posicionamento da Andifes (Associação Nacional dos Dirigentes das Instituições Federais de Ensino Superior) em relação ao Future-se? 
MARD: Não tive acesso a todos os pronunciamentos sobre o Future-se. Do que vi e li, pronunciamentos como os da reitora da UFMG Sandra Goulart, e da reitora da UnB Márcia Abrahão, assim como dos reitores da UFRGS Rui Vicente Oppermann, e da UFSM Paulo Afonso Burmann, são bastante claros sobre os malefícios que sua aplicação causará para a formação da juventude brasileira e o desenvolvimento científico do país. As declarações de João Carlos Salles, reitor da Universidade Federal da Bahia e presidente da Andifes são também muito claras e objetivas, em particular quando enfatiza que a universidade para cumprir suas missões no interesse da sociedade em seu conjunto necessita de autonomia e de recursos públicos compatíveis. Destaque-se também a importância de sua insistência no fato de que a autonomia universitária não se restringe à gestão; ela se estende à pedagogia e à pesquisa e é garantida pela Constituição.

Muito esclarecedores pelas análises fatual e conceitual da iniciativa (em realidade, não se trata nem de programa, nem de projeto, tão imprecisos são seus termos) são os textos elaborados pelos professores Roberto Leher, ex-reitor da UFRJ, e Jaime Giolo, ex-reitor da UFSS (Universidade Federal da Fronteira Sul). Não teria nada a acrescentar ao que revelam estes acadêmicos, que mostram claramente que a proposta governamental terá como resultado colocar instituições públicas sob controle direto do mercado, privatizando bens e recursos públicos. As posições desses acadêmicos, face à gravidade da situação, são moderadas. Limitam-se a mostrar a incoerência e a irregularidade da proposta e a chamar atenção para o absurdo da destruição de um patrimônio público essencial para a formação dos cidadãos e para a construção de uma sociedade justa e independente.

Iludem-se, pois, aqueles, mesmo no meio acadêmico, que pensam que a proposta trará recursos novos para as instituições. É necessário um debate amplo com a sociedade. As instituições públicas precisam mostrar à população o que elas são. Devem mobilizar, por todos os meios, representantes da sociedade civil e discutir com representantes dos Poderes Judiciário e Legislativo, que, apesar de suas falhas notórias, podem evitar que as instituições públicas sejam liquidadas com base em argumentos falsos, consolidando um sistema altamente prejudicial ao país.

Não tenho, assim, nada a acrescentar ao que disseram esses representantes da comunidade acadêmica. Não teria sentido querer analisar artigo por artigo, parágrafo por parágrafo, da proposta governamental. Isto, aliás, já foi feito como afirmei anteriormente. O necessário é analisar seu sentido global com respeito às políticas públicas da educação superior. Limito-me, pois, a chamar atenção para o fato de que a proposta do Future-se se insere num quadro de iniciativas globais, cujos resultados, quando se vê, hoje, o que ocorre no Chile, por exemplo, provocam exclusão e asseguram a consolidação de um neocolonialismo retrógrado no mundo. Em país nenhum, propostas tão radicais como essa foram apresentadas. O Brasil se transforma num laboratório para o que de pior existe em termos de organização da sociedade. E é trágico observar que, 
em momento algum, se propôs à comunidade acadêmica e ao povo brasileiro uma discussão efetiva sobre o estado atual da educação superior e sobre sua pertinência em relação às necessidades da sociedade. O que se busca é promover, de maneira impositiva, um modelo de caráter neoliberal.

Democratização passa a ser dar às instituições privadas o direito de reconhecer diplomas estrangeiros, o que, nos tempos atuais, significa liberalizar totalmente a oferta de disciplinas a distância, que serão seguramente controladas pelos grandes MOOC, que não escondem sua intenção de dominar as universidades no mundo inteiro. Melhorar a gestão significa colocar o patrimônio público duramente construído em mãos de particulares que se ignora quais serão. Para estimular a pesquisa, cria-se a miragem de fundos que proviriam de grupos que jamais se interessaram por desenvolver o conhecimento no país.

Em 5 de novembro de 2019, fui convidado para participar, em Buenos Aires, de um congresso dos professores universitários argentinos com o tema "A universidade como direito: perspectivas desde o Sul". Neste evento, fui chamado a intervir numa mesa-redonda sobre "A universidade latino-americana, atualidade e desafios". Iniciei minha fala recordando alguns fatos históricos: "Em 12 de dezembro de 1888, o procurador-geral da Bélgica, Van Schoor, declarou: 'Existem verdades jurídicas cuja evidência é tão grande que sua demonstração é desnecessária. O axioma é afirmado, mas não demonstrado"”.

Chamei atenção para o fato de que essa afirmação foi feita em um período de consolidação do colonialismo mais brutal da história da humanidade. Durante a ocupação pelos belgas do território que hoje constitui a República Democrática do Congo (antigo Congo Belga), estima-se que mais de 10 milhões de africanos foram exterminados. Nesse contexto, acrescentei, poder-se-ia entender a declaração do advogado belga, mesmo assinalando que ela é moralmente injustificável e legalmente inaceitável. E perguntei aos ouvintes: uma afirmação como essa seria possivel hoje?

Prossegui dizendo que lamentavelmente a resposta à questão é sim, caso se analise o que se passa no Brasil, onde representantes do Poder Judiciário decidiram proferir condenações sem lograr obter provas contra acusados. Basta que intimamente eles estejam convencidos da culpa do acusado. Sendo assim, o que, de fato, passaram a fazer foi primeiro condenar e, depois, montar um processo para formalizar sua decisão.

O mais lamentável é que agora se busca adotar esse método a todos os setores da vida da sociedade. Ele está sendo aplicado também na educação e, particularmente, na educação superior. Seguindo uma tendência universal estimulada por organizações internacionais, decidiram destruir o conceito de educação como bem público, desqualificam a imagem das universidades públicas, tentam jogar a opinião pública contra as universidades, dizendo que são instituições mal geridas, dominadas por privilegiados e responsáveis pela deformação da juventude.

O estímulo à privatização é uma tendência universal estimulada por organizações como o Banco Mundial e a OCDE, mas, no Brasil, ultrapassa todos 
os limites, inclusive com ataques primários contra a memória de Paulo Freire, patrono da educação brasileira, admirado no mundo inteiro e vilipendiado em seu país de origem. Esquecem-se de dizer que, no Brasil, a quase totalidade das pesquisas científicas é feita nas universidades e, na maioria dos casos, em instituições públicas. Deixam de analisar a mobilidade social e a inclusão promovidas por essas instituições. Em 2016, segundo dados então publicados pela Andifes, dois terços dos estudantes das universidades federais, ou seja, $66,19 \%$, provinham de famílias com menos de 1,5 salário mínimo per capita (em 2010, eram apenas 44\%).

Apresentam-se, então, como salvadores dessas instituições e, para isto, divulgam, como se fora uma campanha de lançamento de um produto novo, uma sistemática que, em realidade, visa privatizar tudo, tornando todo o sistema comercial e, em particular, transferindo a grupos privados o patrimônio intelectual e material das universidades públicas. Opõem-se à Constituição, pois as universidades passarão a ser geridas seja pelas organizações sociais, seja por fundações que não dependerão dos conselhos universitários, mas terão de aderir às diretrizes de governança provindas do MEC, ou seja, terão de seguir as instruções que virão dos burocratas instalados no Ministério da Educação.

Observar o que se passa na área da educação no Brasil torna-se, então, um espetáculo deprimente. Numa primeira fase, um ministro medieval tenta restabelecer um sistema equivalente ao que funcionava nas universidades da região antes da reforma universitária de Córdoba de 1918, quando o dogmatismo religioso dominava. Não deu certo, nem podia dar. Agora, tomam-se propostas oriundas do Consenso de Washington, que não deram certo em lugar nenhum, em particular consideradas catastróficas em países como Reino Unido, Estados Unidos ou, mais perto de nós, Chile, e tentam impô-las no Brasil, garroteando as universidades com os cortes e contingenciamentos e deixando claro que, para voltarem a ser beneficiadas com recursos necessários, devem se submeter ao que desejam os dirigentes, inclusive no que diz respeito ao conteúdo do ensino.

O que dizer de tudo isto? É lamentável e é inaceitável! Também não pode dar certo. 